\title{
The effect of manager risk attitudes on range improvement decisions
}

\author{
DANIEL J. BERNARDO AND DAVID M. ENGLE
}

Abstract

Despite the availability of potentially profitable range improvement alternatives, private land ranch managers in the central U.S. are not readily adopting recommended range improvement practices. One explanation for this behavior is that managers may not be willing to accept the increased risk associated with implementing range improvement programs. The objectives of this study were to estimate the expected value and variability of net returns derived from several range improvement practices and use this information to assess the influence that manager risk attitudes have on the selection of range improvement practices. A stochastic range simulation model was used to provide estimates of the expected value and variability of income following the application of several range improvement practices in the Cross Timbers Region. Generalized stochastic dominance procedures were then used to rank these practices for managers characterized by alternative risk attitudes. Results of the analysis illustrate that optimal range improvement practices may be sensitive to manager risk attitudes. Managers willing to accept the possibility of low or negative incomes may prefer more intensive range improvement practices such as application of tebuthiuron for brush management followed by annual prescribed burning. In contrast, risk averse decision makers are inclined to implement lower cost range improvement practices or fail to utilize any range improvement practice.

Key Words: range improvements, brush management, profitability, risk, stochastic simulation, Cross Timbers, risk attitudes

Potentially profitable range improvement programs have been identified in a variety of range regions throughout the western United States (McBryde et al. 1984, Garoian et al. 1984, Torell and McDaniel 1986, Bernardo et al. 1988, Tanaka and Workman 1988). However, despite the availability of potentially profitable range improvement alternatives, managers of private lands in the central U.S. are not readily adopting recommended range improvement practices. For example, recent estimates indicate that production on over $65 \%$ of Oklahoma's 6.3 million hectares of rangeland could be increased by some form of brush control (Soil Conservation Service 1982). It is possible that managers do not base range improvement decisions exclusively on a criterion of profit maximization. Income variability (risk) experienced by the manager may also influence range improvement decisions.

Economic analysis of range improvement practices typically involves the application of investment criteria based upon the assumption of profit maximization (McBryde et al. 1984, Whitson and Scifres 1981, and Garoian et al. 1984). Estimates of additional forage and livestock production over the life of the practice are determined and converted to monetary values using forage allocation and budgeting procedures. This conversion is based on the assumption that each year of the planning horizon will be an average year in terms of weather and the resulting forage production. Prices and livestock performance are also assumed fixed at some predetermined level. Net present value or internal rate of

\footnotetext{
Authors are associate professor, Agricultural Economics Department; and professor, Agronomy Department, Oklahoma State University, Stillwater 74078. Journal Article No. J-5657 of the Oklahoma Agricultural Experiment Station.

Manuscript accepted 16 August 1989.
}

return estimates are then calculated to evaluate the profitability of a practice or rank alternative practices. Because projected benefits are based upon expected production and price levels, these studies do not account for uncertainty inherent in livestock production or the effect of this uncertainty on the economic feasibility of the range investment.

Several recent studies have attempted to incorporate the influence of risk in range management decision making (Conner et al. 1983. Hamilton et al. 1986, and Bernardo et al. 1988). These analyses evaluated range improvement investments under alternative climatic and/or economic scenarios to derive estimates of both the expected value and variability of returns derived from the investment. Lacking in these studies is a means of weighing the tradeoffs between expected value and variability of returns when ranking range improvement investments. The problem facing the manager is selecting a range improvement practice that provides adequate expected net returns while also maintaining risk (net return variability) below some acceptable level. To determine optimal range improvement practices, criteria are needed that explicitly incorporate the influence of both expected net returns and risk.

An individual's risk attitudes reflect his preference for acceptable increases in the level of risk which accompany increases in expected returns. Empirical studies focusing on the measurement of risk attitudes have found that agricultural producers are characterized by a wide range of perceptions concerning risk (King and Robison 1981, Halter and Mason 1978). Risk attitudes may vary among individuals depending upon, among other things, their long-run management objectives and current financial situation. For example, a manager in a strong financial position may be more willing to take risks, while those in a weaker financial situation desire to avoid the occurrence of low net returns. Producers evaluating brush management strategies typically may choose from several teatment alternatives differing in terms of both cost and vegetation response. Adopting each alternative will have different consequences on both the expected value and variability of future ranch incomes. As a result, different practices may be preferred by managers having different risk attitudes. For example, producers averse toward risk may select range improvement programs that provide a low, but stable, annual income. Conversely, producers willing to accept a large amount of risk may invest in high-cost range improvement practices with the objective of significantly increasing the productivity of the management unit.

The objectives of this study are twofold. First, to estimate the expected net return and risk associated with several alternative range improvement programs. Second, to use this information to assess the influence that producer risk attitudes may have on the selection of range improvement practices. Optimal brush management treatments are identified for producers characterized by alternative risk attitudes in the Cross Timbers of central Oklahoma. This analysis may illustrate the role that alternative risk attitudes play in the wide variation of range improvement programs adopted by producers in the region.

\section{Methods and Procedures}

A stochastic ranch simuiation modei was used to provide esti- 
mates of both the expected value and variability of income following application of range improvement practices. Through repeated iteration of the model, a probability distribution of income generated by each range improvement practice was derived. Generalized stochastic dominance procedures were then applied to the distributions to rank the various practices according to their risk-return properties.

\section{Stochastic Ranch Simulation Model}

Stochastic simulation is an analytical technique that involves the mathematical representation of a system, wherein critical stochastic variables are represented using specified probability distributions. In this application, a stochastic simulation model was developed to represent the economic performance of a representative ranch following the application of various range improvement practices. The simulation model was programmed to calculate annual gross receipts, variable costs, and overhead costs under stochastic economic and environmental conditions and is a modified version of the model reported in Bernardo et al. (1988). The simulation is conducted in annual time steps over a 15 -year planning horizon. A schematic diagram of the data flow of the simulation model is presented in Figure 1.

To simulate livestock production following a range improvement practice, relationships are specified to represent livestock and vegetation response, as well as the movement of critical economic variables, over the life of the range improvement. The simulation is initiated by specifying a base ranch situation defining the initial range condition, price levels, and resource endowments (land, capital, etc.) of the representative ranch. At the beginning of each year, a set of random variables defining the current economic and production conditions are derived by the stochastic process generator. Random variables included in the analysis are monthly precipitation and temperature, forage standing crop, cattle prices, supplemental feed prices, death loss, and stocker weight gains. Multivariate probability distributions defining these random variables are specified for each year of the planning horizon, reflecting the changing economic and production conditions over the life of the range improvement investment. Random variables from the stochastic process generator provide the principal input into the cost and return simulation model. The ranch operation is simulated sequentially; the current year's ending financial and resource situation becomes the beginning position for the following year. Annual net return estimates over the life of the range improvement practice are employed in the investment model to determine the total income contribution of the range improvement practice.

The simulation model may be used to evaluate alternative range improvements by programming relationships and probability distributions defining forage and livestock response for the practice into the model. The complete management plan, defining marketing and production practices employed by the producer, is also specified. Through repeated iteration of the model, a probability distribution of net returns derived from the range improvement practice (expressed in terms of the 15-year net present value) may be estimated. This distribution defines the possible economic outcomes that could result if the range improvement is implemented on the representative ranch. Optimal range improvement practices may be identified by comparing the distributions derived for alternative practices.

\section{Forage and Livestock Response}

Forage and animal response relationships employed in the analysis were based upon experimental relationships from previous research (Elwell et al. 1970, Elwell et al. 1974, Stritzke et al. 1975) and an on-going long-term study on the Cross Timbers rangeland in northcentral Oklahoma (Stritzke et al. 1987, Engle et al. 1987).

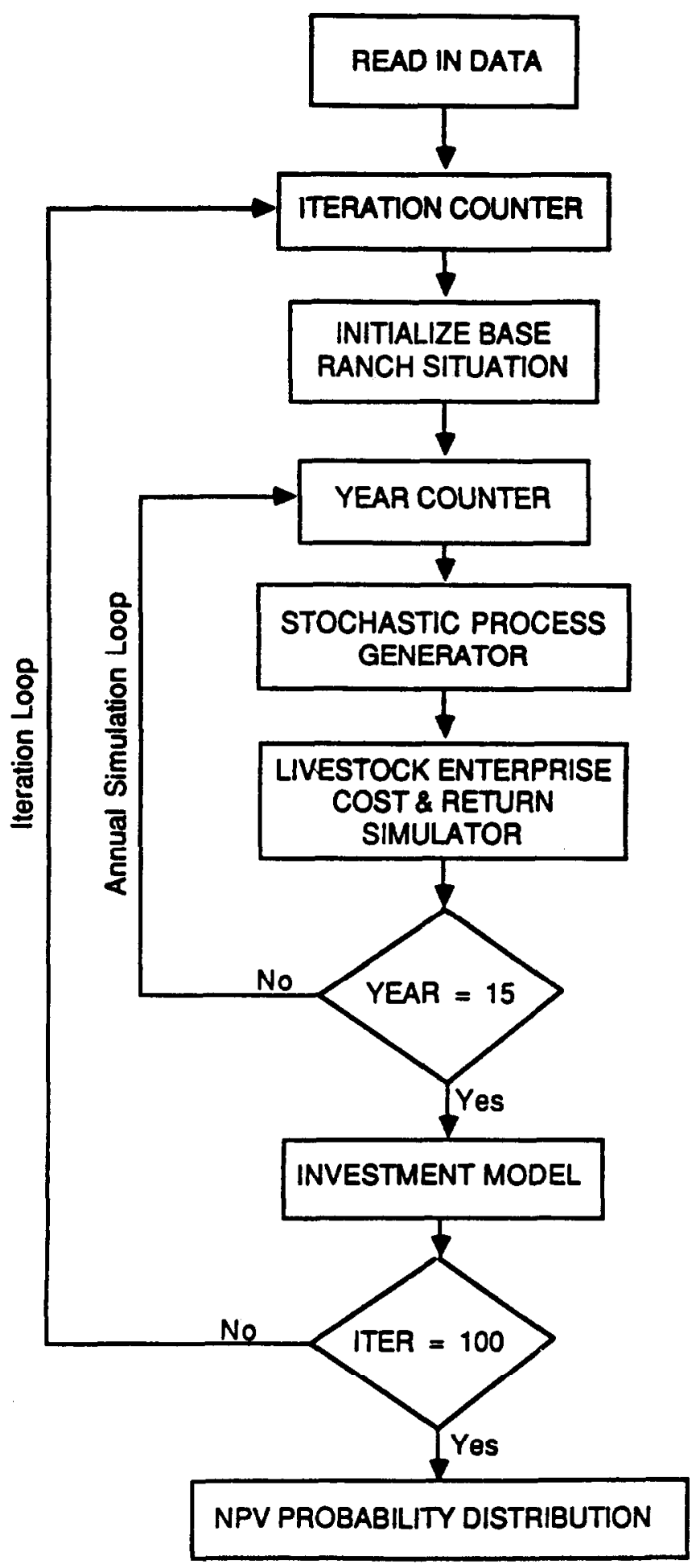

Fig. 1. Schematic of the data flow of the stochastic simulation model.

Four range improvement practices were evaluated: (1) a single (application of tebuthiuron ( $N-[5-(1,1-$ dimethylethyl)-1,3,4-thiadiazol-2yl\}-N,N-dimethylurea) at a rate of $2.2 \mathrm{~kg} /$ ha of active 
ingredient, (2) application of tebuthiuron followed by annual spring prescribed burning, (3) a single application of triclopyr ([3,5,6-tricloro-2-pyridinyl)oxy] acetic acid) at a rate of $2.2 \mathrm{~kg} / \mathrm{ha}$ of active ingredient, and (4) application of triclopyr followed by annual spring prescribed burning. The application of each practice, as well as a no-improvement practice alternative, was evaluated on pastures composed of shallow savannah and sandy savannah range sites.

Both range sites are dominated by an overstory of post oak (Quercus stellata) and blackjack oak ( $Q$. marilandica), although the sandy savannah has less post oak and a greater cover of rough-leaf dogwood (Cornus drummondii) and chinquapin oak (Q. muehlenbergii)(Ewing et al. 1984). These sites normally occur in a mosaic, with the sandy savannah site located on lower slopes and ridge shoulders with deeper soils along streams. The shallow savannah site is located on ridges and upper slopes with shallow soils. Total woody canopy cover is greater and herbaceous cover and production is less on sandy savannah, although site potential is greater on this site because of the deeper soils and run-in topographic position. Selective brush herbicides such a triclopyr and tebuthiuron induce regression toward tallgrass prairie on both sites, but tebuthiuron produces a more complete and longer-term forage release from brush competition. Prescribed burning provides secondary control of resistant and resprouting brush species, but burning is less effective following triclopyr than tebuthiuron because the initial kill of understory brush species that reduce forage and fine fuel accumulation is less with triclopyr.

The producer is assumed to have 3 alternative 810 -hectare $(2,000$ acre) pastures available for treatment, each comprised of a different composition of the 2 range sites. Alternative compositions of the pastures (or management areas) are: (1) all shallow savannah, (2) $75 \%$ shallow savannah and $25 \%$ sandy savannah, or (3) equal quantities of each range site. These compositions represent the typical range of proportions of the 2 sites that would comprise a single management unit in the Cross Timbers study region. Thus, 15 range improvement alternatives (4 range improvement practices on the 3 pastures, plus the 3 no-treatment strategies) were evaluated. To facilitate discussion, each range improvement alternative is assigned an acronym consisting of: (1) the chemical treatment, (2) an indicator of whether annual prescribed burning is employed, and (3) the description of the management unit. For example, TEB-B-100 represents the application of tebuthiuron followed by annual prescribed burniñg on the $100 \%$ shallow savannah range management unit.

Response curves were developed to represent changes in forage production resulting from each treatment strategy. The response curves depict the path of expected forage peak standing crop over the time horizon of the analysis and are presented for shallow and sandy savannah range sites in Figures $2 . a$ and 2.b, respectively. Forage production values for the 5 years following application of each practice are actual standing crop measurements of herbaceouss vegetátion from the Cross Timbers study (Engie et al. 1987 and unpublished data). Forage yields in the remaining years of each practice's life represent a consensus of "expert opinion" projections based upon 3 decades of brush control research results in the Cross Timbers of Oklahoma (Elwell et al. 1970, Elwell et al. 1974, Stritzke et al. 1975, Engle et al. 1987).

Producers experience 2 major sources of variability in forage production following the application of range improvement practices. First, as a result of climatic variability, annual forage production on a particular range site may differ considerably across years. Twenty-two years of hay yield data from a tallgrass prairie range site located in the study region indicated a mean standing crop of $3,680 \mathrm{~kg} / \mathrm{ha}$ and a standard deviation of $1,260 \mathrm{~kg} / \mathrm{ha}$ (Harper 1957). This source of uncertainty occurs regardless of whether a range improvement has been initiated, and will increase in absolut terms following implementation of a range improvement practic (Conner et al. 1983, Bernardo et al. 1988). A second source o variability arises from variation in the overall effectiveness of th range improvement practice in suppressing brush and promotin! forage production. The success of a range improvement practic (i.e., the rate and magnitude of increases in forage production ove: the life of the practice) may be affected by climatic events in year before, during, and immediately following the application of thi practice.

Annual variation in forage production resulting from climati variability was derived from a hay yield model developed by Powell et al. (1986) which employs monthly temperature and pre cipitation data. Powell's model was developed from data collectec in close proximity (Payne County, Oklahoma) to the Cros! Timbers study site (Harper 1957). The Harper study site wa: characterized by an average hay yield of $3,680 \mathrm{~kg} / \mathrm{ha}$ and ha! similar site potential as the Cross Timbers site. To apply the mode to range improvement scenarios where annual forage productior changes over time, the model was transformed to derive estimate: of "relative" annual peak standing crop (the ratio of annual has yield predicted from Powell's model to average hay yield from Harper's data). Forty-seven years of historical weather data (1942-1987) from Stillwater, Oklahoma, provided the climatic input for the model. To account for cyclical weather patterns, 3: different 15-year weather sequences were developed from the data: each sequence was assigned an equal probability of occurrence and randomly selected at the beginning of each iteration. Weather data from each year of the sequence were employed in the model tc develop estimates of relative hay yield. These estimates were ther multiplied by average annual forage peak standing crop (deter. mined from the response curves in Fig. 2) to derive estimates of annual forage peak standing crop. The resulting series of forage peak standing crop estimates reflect the increases in average annua] peak standing crop depicted in the response curves, as well as expected variability around these values.

To represent variation in treatment success, 3 response curves were developed for each treatment alternative. These response curves represent alternative paths of forage production under low, moderate, and high levels of treatment effectiveness. Response curves presented in Figures 2.a and 2.b reflect a moderate leve] forage response. Herbaceous understory response under low (high) levels of treatment eff́ectiveness is assumed to be $20 \%$ below (above) the values shown in Figure 2. At the initiation of each iteration, a response curve is randomly selected from the 3 alternatives and used to generate forage production estimates over the 15-year time horizon.

Livestock production was assumed to consist of a summer stocker enterprise. Stockers are purchased in mid-April at an average weight of $204 \mathrm{~kg}$ and grazed 150 days until mid-September. Variability in steer performance was represented using triangular probability distributions of seasonal weight gain as estimated in Bernardo et al. (1988). Separate distributions are specified for steers grazing burned and unburned pastures to reflect improved gains from burning (McCollum 1987, McCollum et al. 1987, Smith and Owensby 1972, Owensby and Smith 1979). Mean annual weight gains of 113.4 and 102.1 kilograms per steer were specified in the burn and no-burn distributions, respectively. Stocking rates were determined by allocating $25 \%$ of total forage production (peak standing crop) to use by livestock (Kothmann 1984) assuming total seasonal forage consumption of $1,200 \mathrm{~kg} / \mathrm{steer}$.

\section{Returns and Costs}

Values derived from the production response models were combined with stochastically derived prices to estimate annual net returns. Average per-head net returns in year $t\left(A N R_{t}\right)$ were esti- 

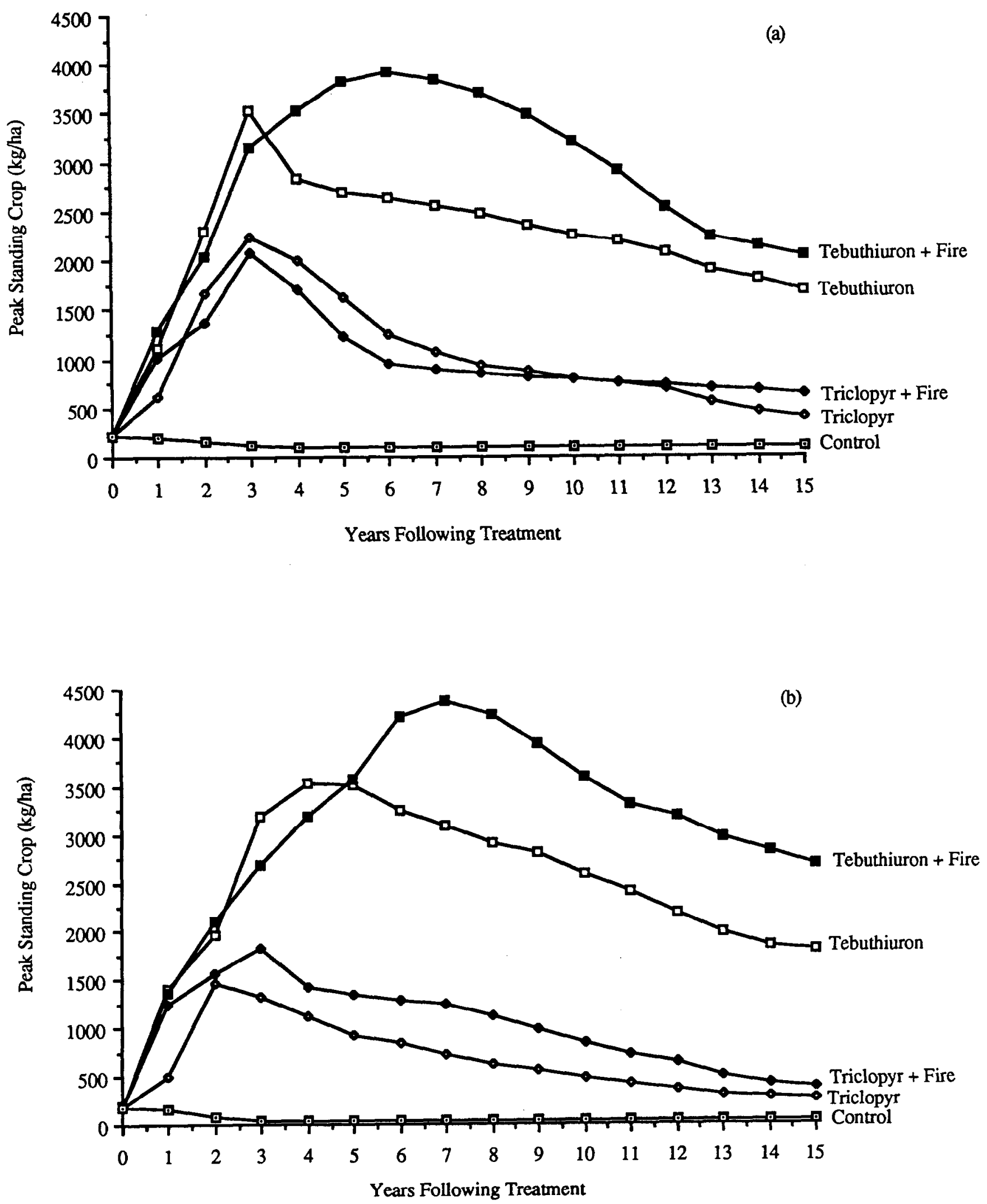

Fig. 2. Response curves for 5 alternative range improvement strategies on shallow savannah (a) and sandy savannah (b) range sites. 
mated as:

$$
A \bar{N} R_{t}=\left[\tilde{P}_{a t} \times\left(204+\bar{G}_{t}\right) \times\left(1-\tilde{D}_{t}\right)\right]-204 \tilde{P}_{\mathrm{ct}}-C\left(\bar{G}_{t} \tilde{P}_{f t}\right)
$$

where, $\tilde{\mathbf{P}}_{\mathrm{at}}, \tilde{\mathbf{P}}_{\mathrm{ct}}$, and $\tilde{\mathbf{P}}_{\mathrm{ft}}$ are prices of feeder steers, calves, and supplemental feeds (\$/ kg), respectively; $\widetilde{G}_{t}$ is seasonal weight gain $(\mathrm{kg} / \mathrm{head}) ; \tilde{D}_{\mathrm{t}}$ is the death loss; and $\mathrm{C}(\mathrm{)}$ is an expression relating stocker production costs to stocker weight gain and feed prices $(\$ /$ head). Costs incorporated in $\mathrm{C}($ ) include supplemental feed costs, hauling and marketing costs, interest on operating capital, machinery costs, and veterinary expenses. Cattle and feed prices were drawn from a multivariate normal distribution estimated from historical price data. Mean values of the distribution were specified from price models that reflect the expected values of each price over the time horizon. Summary statistics of stochastic variables employed in the model are reported in Table 1 . Annual costs

Table 1. Summary statistics of stochastic variables included in the simulation model.

\begin{tabular}{lcc}
\hline \hline Variable & Mean & $\begin{array}{c}\text { Standard } \\
\text { deviation }\end{array}$ \\
\hline Seasonal weight gain: & & \\
$\quad$ burned pasture $(\mathbf{k g} / \mathbf{h d})$ & 113.6 & 15.20 \\
$\quad$ unburned pasture $(\mathbf{k g} / \mathbf{h d})$ & 102.7 & 13.90 \\
Steer price, $272-317 \mathbf{~ k g}(\mathbf{\$} / \mathbf{k g})$ & 1.549 & 0.292 \\
Calf price, $181-227 \mathbf{~ k g}(\mathbf{\$ g g})$ & 1.692 & 0.310 \\
Prairie hay $(\$ / \mathbf{k g})$ & 0.064 & 0.011 \\
Protein supplement $(\mathbf{\$} / \mathbf{k g})$ & 0.292 & 0.045 \\
\hline
\end{tabular}

of stocker production (excluding the calf cost) are $\$ 79.00$ per head when stochastic variables are held at their mean values.

Per-head returns are converted to total net returns from stocker production in year $t\left(T_{N R}\right)$ using the following relationship:

$$
T \tilde{N} R_{t}=\left[A \tilde{N} R_{t} \times S_{t}\left(\tilde{R}_{t}\right) \times A\right]-\left[\left(P_{a} \times A\right)+\left(P_{b} \times B_{t}\right)\right]
$$

where, $S_{t}$ is the stocking density (steers/ha) expressed as a function of model-generated estimates of annual forage production $\left(R_{t}\right) ; A$ is pasture size (hectares); $P_{a}$ and $P_{b}$ are the costs of pasture maintenance and burning ( $\$ /$ ha); and $B_{i}$ indicates the number of hectares burned. The annual cost of prescribed burning was estimated to be $\$ 5.73$ per hectare (Bernardo et al. 1988). Annual net return estimates are discounted and summed and the cost of chemical treatment subtracted to derive an estimate of the net present value (NPV) of returns generated from the range improvement practice. That is,

$$
N P V=\sum_{t=1}^{n}\left[T N R_{t} /(1+r)^{t}\right]-\left(P_{T} \times T\right)
$$

where, $r$ is the discount rate, $n$ is the time horizon (number of years) of the analysis, $P_{T}$ is the cost of chemical treatment $(\$ / h a)$, and $T$ indicates the number of hectares chemically treated. Application and chemical costs of the tebuthiuron and triclopyr treatments were set at $\$ 160.55$ and $\$ 86.45$ per hectare, respectively (Stritzke p.c.).

\section{The Stochastic Dominance Model}

Repeated iteration of the simulation model provides a probability distribution of net present value outcomes under each range improvement alternative. The derived distributions provide information concerning the relative profitability and risk associated with adopting the range improvement alternatives. The decision maker is faced with the dilemma of selecting the range improvement practice that provides levels of expected returns and risk consistent with his risk attitudes. Generalized stochastic domi- nance is an evaluative criterion that orders uncertain choices based upon decision-maker risk attitudes as well as expectations concerning the probability of outcomes under each action choice (King and Robison 1981).

Generalized stochastic dominance provides a practical means of applying expected utility theory to decision problems. The expected utility model is the foundation of the majority of economic risk analyses and is premised on the assumption the decision makers choose actions to maximize their expected utility. Expected utility is an ordinal index of satisfaction that not only accounts for the expected value of an action, but the probability of alternative outcomes as well. The expected utility of a particular action $\mathrm{j}$ may be represented as

$$
(E U)_{j}=f\left(u_{j}, \sigma, M 3_{j}, \ldots\right)
$$

where $u_{j}, \sigma_{j}, M 3_{j}, \ldots$ represent the mean, variance, skewness, and higher moments of the probability distribution of outcomes for action $\mathrm{j}$ (Young 1984). In this case, the outcome of importance is the NPV of the 15-year stream of net returns generated following application of the range improvement practice or following no improvement practice in the case of the no-treatment alternative. Range improvement alternatives (actions) are ranked according to their expected utility with the highest level the most preferred.

Risk is measured in the expected utility model by the moments of the probablity distribution of outcomes. A decision maker's risk attitudes are reflected in the shape of his utility function, and hence, the relative weights assigned to the various moments of the probability distribution. For example, the utility function of producers with a strong aversion toward risk would be specified to penalize actions characterized by a high probability of low income occurrences. Therefore, decision attitudes will assign different levels of expected utility to actions, resulting in the possibility of different preferred actions.

Decision makers may be classified according to their risk attitudes as risk averse, risk preferring, or risk neutral. Risk averters are characterized as more cautious individuals with preferences for less risky sources of income. In general, these decision makers will sacrifice some amount of expected income to reduce the probability of less income or loss. When comparing alternatives with similar expected incomes, risk preferrers select the alternative with some probability of higher incomes, even though they must accept an increased probability of lower incomes as well. These producers desire higher expected incomes and are willing to take additional risk to attain them. Risk neutrality refers to the intermediate case. Individuals classified as risk neutral prefer the alternative with the highest expected return, despite the probabilities of gain or loss. For a more detailed discussion of risk attitudes and expected utility theory, the reader is referred to Robison et al. (1984).

Generalized stochastic dominance may be used to derive optimal range improvement practices for classes of decision makers having similar risk attitudes. Risk classifications are defined by specifying the upper and lower bounds of the decision maker's risk aversion function.' These bounds are determined from empirical studies where actual risk attitudes are elicited from managers and translated into the measurement scale (King and Robison 1981). Once the risk preferences have been specified, an ordering of 2 practices can be made strictly on the basis of the properties of their probability distributions. Under such an ordering, one alternative will dominate the other, or the criterion will not be able to order the 2 alternatives and both will be considered efficient. Through a series of pair-wise comparisons, an optimal set of range improvement alternatives may be derived.

TThe absolute risk aversion function $r(y)$ is defined by the expression $r(y)=u$ " $(y) / u^{\prime}(y)$, where $u^{\prime}(y)$ and $u^{\prime \prime}(y)$ are the first and second derivatives of the decision maker's utility function. 


\section{Results and Discussion}

The simulation model was run over a 15-year time horizon to evaluate the economic feasibility of each of the 15 range improvement alternatives. For each alternative, 100 iterations of the model were completed to derive a probability distribution of NPV outcomes. Since all prices and costs are expressed in real (noninflated) terms, a real discount rate of $4 \%$ was used to estimate the net present value of the 15-year return stream. A summary of the distribution of the net present values derived under each of the 15 range improvement alternatives is presented in Table 2. For each practice, the mean, standard deviation, and range of the NPV of the stream of annual net returns is given.

Table 2. Summary of net present value distributions derived from alternative range improvement practices on $\mathbf{8 1 0}$ ha pasture in the Cross Timbers.

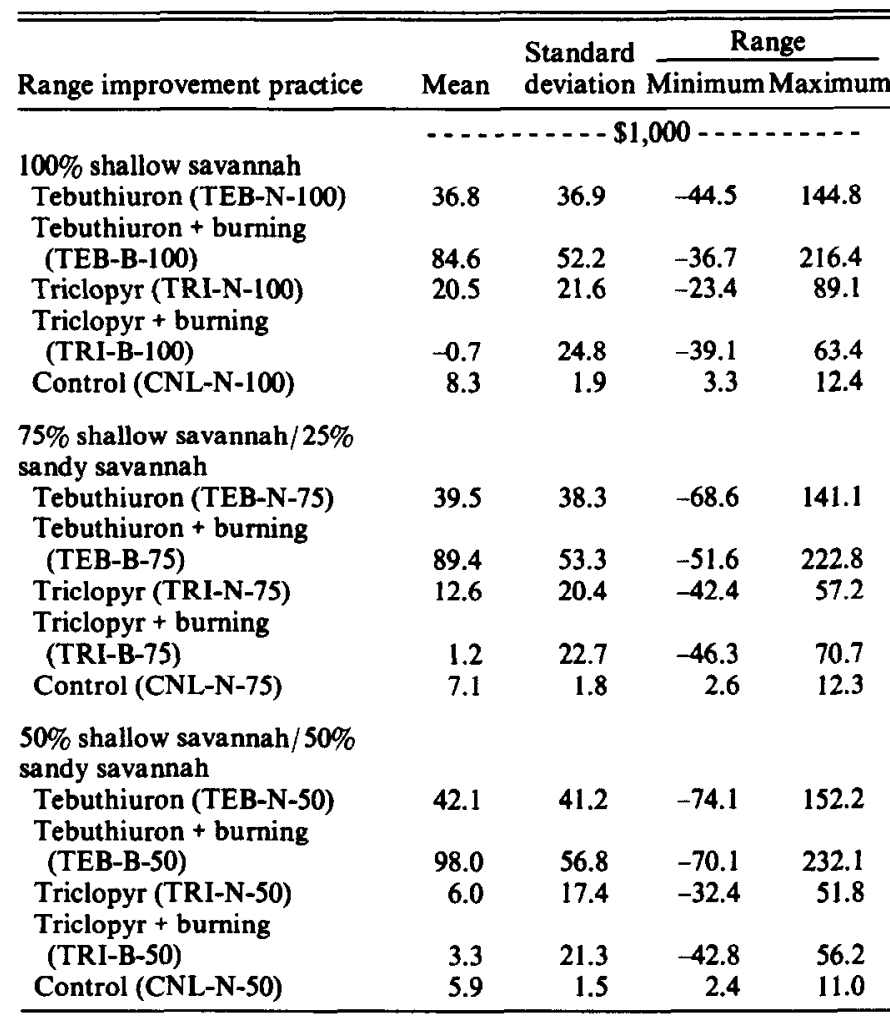

Potential income levels vary widely among the available range improvement alternatives. Application of tebuthiuron followed by annual prescribed burning (TEB-B) is the most profitable range improvement practice available for all range site compositions. For this practice, the mean net present value of the 15 -year return stream derived from livestock production on the 810-hectare pasture ranges from $\$ 84,571$ (TEB-B-100) to $\$ 98,023$ (TEB-B-50). The profit maximizing producer selecting a single range improvement alternative would apply tebuthiuron followed by annual prescribed burning on the $50 \%$ shallow savannah $/ 50 \%$ sandy savannah management unit. This result reflects both the large increases in annual forage production observed over the life of the chemical treatment as well as improved weight gains of stockers grazing the pastures. The application of triclopyr followed by annual burning and the no-treatment alternatives have the lowest level of expected returns. In the absence of range improvements, producers employ very low stocking rates, and hence, receive low levels of annual income from the 810-hectare pasture. Range site composition also affects average expected returns derived from range improvement practices. These differences primarily reflect differences in the level of expected forage production of the 2 range sites, as shown in Figures $\mathbf{2 a}$. and $\mathbf{2 b}$.
Range improvement programs also have an impact on the variability of returns earned from livestock production. The standard deviation and range of NPV outcomes reported in Table 2 provide an indicator of the relative income risk associated with each range improvement alternative. Livestock production on untreated pastures provides the most stable source of income. Income variability is augmented as a result of applying chemical treatments. In addition to providing the highest expected return, application of tebuthiuron followed by annual burning also results in the greatest range and standard deviation of income. Because of the high cost of tebuthiuron application, the possibility exists that income from livestock production will not be sufficient to cover the initial investment. Conversely, very large NPVs may result when favorable livestock prices occur in combination with high forage production. Practices involving the application of tebuthiuron without an accompanying burning program yield the next highest level of income variability, again reflecting the large initial investment. Triclopyr + burning and triclopyr alternatives result in moderate levels of income variability.

Results from applying the generalized stochastic dominance model to the derived probability distributions are presented in Table 3. Optimal range improvement alternatives are reported for

Table 3. Optimal range improvement strategies for decision makers characterized by alternative risk attitudes.

\begin{tabular}{ll}
\hline \hline $\begin{array}{l}\text { Risk classification } \\
\text { of decision maker }\end{array}$ & $\begin{array}{l}\text { Optimal set of range } \\
\text { improvement alternatives }\end{array}$ \\
\hline Risk preferring & TEB-B-50 \\
Risk neutral & TEB-B-100, TEB-B-75, TEB-B-50 \\
Slightly risk averse & TEB-B-100, TEB-B-75, TRI-N-100 \\
Strongly risk averse & TRI-N-100, CNL-N-100, CNL-N-75
\end{tabular}

Upper and lower bounds on the absolute risk aversion function defining the risk classifications are risk preferring ( -.0008 to -.0001$)$, risk neutral $(-.0001$ to .0001$)$, slightly risk averse (.0001 to .0004$)$, and strongly risk averse $(.0004$ to .001$)$.

4 risk classifications. ${ }^{2}$ The efficient set of each classification includes the strategies that maximize expected utility for decision makers whose risk attitudes conform to the restrictions specified for that criterion. By comparing the efficient sets derived for each risk classification, inferences can be made concerning the influence of risk attitudes on range improvement decisions.

The application of tebuthiuron on mixed savannah rangeland followed by annual prescribed burning (TEB-B-50) is identified as the optimal range improvement practice for risk-preferring decision makers. As indicated by the range and standard deviation of NPVs (see Table 2), this strategy is characterized by the largest amount of variability of the 15 alternatives evaluated. TEB-B-50 also results in the highest expected net present value, indicating that optimal range improvement decisions under assumptions of risk preference are consistent with profit maximization. Risk preferrers are willing to accept the high level of risk associated with TEB-B-50 to gain an opportunity of realizing the large net present values that are also attainable.

Under assumptions of risk neutrality, the optimal set of range improvement practices is expanded to include the remaining tebuthiuron + burning strategies (TEB-B-100 and TEB-B-75). In this case, the stochastic dominance model is not capable of differentiating among the 3 strategies. Application of tebuthiuron followed by annual prescribed burning on any of the $\mathbf{3}$ management units is considered an efficient practice.

Range improvement practices identified as efficient by slightly

${ }^{2}$ Each risk classification was defined in terms of intervals measured by the upper and lower bounds on the absolute risk aversion function (King and Robison 1981). The 4 risk intervals identified in Table 3 are based on the empirical work of Cochran et al. (1985). 
risk-averse decision makers are TRI-N-100, TEB-B-100, TEB-B75. The profit maximizing range improvement alternative (TEB-B50) is replaced in the optimal set by the application of triclopyr on shallow savannah rangeland (TRi-N-100). TEB-B-50 has the highest probability of negative NPV outcomes among the available range improvement alternatives. Although acceptable to the riskpreferring and risk-neutral decision maker, this level of risk is not acceptable to the risk averter. Application of triclopyr results in a large decrease in expected income compared to tebuthiuron + burning, but also provides significant reduction in the variability of NPV outcomes. TRI-N-100 has the lowest probability of negative NPV outcomes of any of the alternatives employing a range improvement practice. Such a tradeoff between expected returns and risk is consistent with the preferences of the risk averter.

The optimal set of range improvement alternatives adopted under strong risk aversion differs considerably from those identified under the other risk classifications. Range improvement alternatives identified as efficient by strongly risk averse decision makers are TRI-N-100, CNL-N-100, and CNL-N-75. Range improvements involving the application of tebuthiuron are no longer considered optimal. Strongly risk averse producers are not willing to accept the high probability of low (or negative) NPV outcomes associated with these practices. CNL-N-100 and CNL-N-75 do not involve any form of range improvement and provide the producer a relatively low, but stable source of income. Strategies comprising the efficient set are characterized by infrequent occurrences of low NPVs, indicating that producers having a stronger aversion toward risk place considerable emphasis on avoiding low returns. Six of the 15 range improvement alternatives were included in 1 or more of the 4 sets of efficient range improvement practices. The remaining alternatives were dominated by 1 or more strategies under each of the 4 risk attitude classifications, and thus, are non-optimal under all risk classifications.

\section{Conclusions}

Both the expected value and variability of net present value outcomes differ considerably across range improvements evaluated. While providing the highest expected return, application of tebuthiuron followed by annual prescribed burning also results in the largest amount of risk. Tebuthiuron applications provide the next largest expected income, followed by the triclopyr, notreatment, and triclopyr + burning alternatives. The triclopyr and triclopyr + burning alternatives result in moderate levels of income variability, while risk is minimized when range improvements are not employed.

Optimal range improvement strategies are sensitive to decision maker risk attitudes. Over the range of risk attitudes evaluated, optimal range improvement programs vary from an intensive practice of the combined use of tebuthiuron and prescribed burning to the extensive alternative of no range improvement practice. Clearly, there exists no dominant optimum range improvement practice; the optimal range improvement program for a specific producer is conditional upon his/her attitudes concerning risk.

It is possible that much of the variation in range improvement programs employed by managers within a specific production region may be explained by observing differences in risk-return situations and individual risk attitudes. Economic problems facing the livestock sector have had significant adverse effects on the financial position of many decision makers. These individuals apparently perceive the risks associated with intensive range improvement practices and are unwilling to endanger the long-run survivability of their ranch enterprise. These decision makers are typically risk averse and adopt low-cost improvement practices or fail to utilize any range improvement practices. On the other hand, producers willing to accept a possibility of low or negative returns prefer intensive range improvement practices that will increase the profitability of the ranching operation. Thus, it is possible that producers within a region may adopt a wide variation of range improvement practices and still be making rational economic decisions.

The results of this analysis illustrate the dangers involved in ignoring the risk associated with range improvement practices and in basing range management prescriptions solely on a criterion of profit maximization. In this example, the practice that results in the largest NPV involves the application of tebuthiuron followed by annual prescribed burning. However, this practice would be preferred by only a limited number of producers when risk considerations are incorporated.

To counter the increasing economic instability of the livestock sector, ranch operators need to adopt improved methods of managing risk. Effective risk management requires information concerning the influence of various production practices on both the expected level and variability of ranch income. Risk analysis has considerable potential for providing decision makers information necessary for improved evaluation of range improvement practices, as well as other income producing practices. Further research is needed focusing on the measurement of risk, elicitation of risk attitudes, and identification of efficient production practices.

Relationships employed in this study are adequate to illustrate that producer risk attitudes are important factors in identifying efficient range improvement practices. The results of this analysis, however, must be interpreted in light of the assumptions employed. Limited data are available from which to specify relationships defining the variability of forage production and livestock performance following a range improvement practice. Although relationships used in this study are based on the best available data, additional research is needed to provide data to refine these estimates. Application of the model to different range sites, initial range condition, and economic situations would require respecification of the model and could result in different sets of risk efficient range improvement practices.

\section{Literature Cited}

Bernardo, D.J., D.M. Engle, and F.T. McCollum 1988. An economic assessment of risk and returns from prescribed burning on tallgrass prairie. J. Range Manage. 41:178-183.

Cochran, M.J., L.J. Robison, and W. Lodwick. 1985. Improving the efficiency of stochastic dominance techniques using convex set stochastic dominance. Amer. J. Agr. Econ. 67:289-295.

Conner, J.R., C.A. Pope, G.L. McBryde, W.T. Hamilton, and C.J. Scifres. 1983. An economic assessment of brush control practices in south Texas. Paper presented at 1983 Annual Meetings of the Western Agr. Econ. Assoc.

Elwell, H., W.E. McMurphy, and P.W. Santelmann. 1970. Burning and 2,4,5-T on post and blackjack oak rangeland in Oklahoma. Oklahoma Agr. Exp. Sta. Bull. B-675.

Elwell, H., P.W. Santelmann, J.F. Stritzke, and H. Greer. 1974. Brush control research in Oklahoma. Oklahoma Agr. Exp. Sta. Bull. B-712.

Engle, D.M., J.F. Stritzke, and F.T. McCollum. 1987. Brush management on the Cross Timbers Experimental Range: II. Herbaceous plant responses. Oklahoma Agr. Exp. Sta. MP-119:103-109.

Ewing, A.L., J.F. Stritzke, and J.D. Kulbeth. 1984. Vegetation of the Cross Timbers Experimental Range Oklahoma. Oklahoma Agr. Exp. Sta. Res. Rep. P-856.

Garoian, L., J.R. Conner, and C.J. Scifres. 1984. Economic evaluation of fire-based improvement systems for Macartney rose. J. Range Manage. 37:111-115.

Halter, A.M., and R. Mason. 1978. Utility measurement for those who need to know. West. J. Agr. Econ. 3:99-109.

Hamilton, W.T., J.R. Conner, J.W. Stuth, G.L. McBryde, and A.J. Vega. 1986. Incorporating precipitation-induced variation in annual forage production into economic analyses of range improvement practices. Texas Agr. Exp. Sta. Res. Bull. 1519.

Harper, H.J. 1957. Effects of fertilization and climatic conditions on prairie hay. Oklahoma Agr. Exp. Sta. Bull. B-492.

King, R.P., and L.J. Robison. 1981. Implementation of the interval approach to the measurement of decision maker preference. Michigan State Univ. Res. Rep. 418. 
Kothmann, M.M. 1984. Concepts and principles underlying grazing systcms. p. 903-916. In: NRC/NAS, Developing Strategics for Rangeland Management. Westview Press. Boulder, Colo.

McBryde, G.L., J.R. Conner, and C.J. Scifres. 1984. Selected brush management practices for eastern south Texas. Texas Agr. Exp. Sta. Bull. 1468 .

MeCollum, F.T. 1987. Integrating livestock decisions with brush management in the Cross Timbers, p. 32-41. In: D. Rollins (ed.), Proc. of Brush Management in the Cross Timbers. Oklahoma Coop. Ext. Serv. Circ. E-862.

McCollum, F.T., D.M. Engle, and J.F. Stritzke. 1987. Brush management on the Cross Timbers Experimental Range: III. Carrying capacity and steer performance. Oklahoma Agr. Exp. Sta. MP-110:110-113.

Owensby, C.E., and E.F. Smith. 1979. Fertilizing and burning Flint Hills bluestem. J. Range Manage. 32:254-258.

Powell, J., S.J.Stadler, and P.L. Claypool. 1986. Weather factors affecting 22 years of tallgrass prairie production and quality. J. Range Manage. 39:354-361.

Robison, L.J., P.J. Barry, J.B. Kliebenstein, and G.F. Patrick. 1984. Risk attitudes: concepts and measurement approaches. In: P.I. Barry (ed.), Risk management in agriculture. Iowa State Univ. Press, Ames.
Smith, E.F., and C.E. Owensby. 1972. Effect of fire on true prairie grasslands. Tall Timbers Fire Ecology Conf. 12:9-22.

Soil Conservation Service. 1982. Oklahoma resource inventory. Statistical data tables. NRI-1982. USDA, Stillwater, Okla.

Stritzke, J.F., D.M. Engle, and F.T. McCollum. 1987. Brush management on the Cross Timbers Experimental Range: I. Brush problems and responses to herbicides. Oklahoma Agr. Exp. Sta. MP-1 19:99-102.

Stritzke, J.F., W.E. McMurphy, and R.W. Hammond. 1975. Brush control with herbicides: Sarkey's research and development report. Oklahoma Agr. Exp. Sta. MP-95.

Tanaka, J.A., and J.P. Workman. 1988. Economic optimum big sagebrush control for increasing crested wheatgrass production. J. Range Manage. 41:172-178.

Torell, L.A., and K.C. McDaniel. 1986. Optimal timing of investment to control honey mesquite. J. Range Manage. 39:378-382.

Whitson, R.E., and C.J. Scifres. 1981. Economic comparison of honey mesquite control methods with special reference to the Texas Rolling Plains. J. Range Manage. 34:415-420.

Young, D.L. 1984. Risk concepts and measures for decision analysis. In: P.I. Barry (ed.), Risk management in agriculture. Inwa State I Iniv. Press, Ames. 